\title{
Study on Strategy for Development of Leisure Sports Specialty in Universities from a Perspective of Core Competence
}

\author{
Xufeng Gu \\ School of Physical Education \\ Changzhou University \\ Changzhou, Jiangsu, China, 213164
}

\begin{abstract}
Proceeding from the development and talents training of leisure sports specialty and using the core competence theory, the paper suggests based on analysis that: to guarantee the existence and development of leisure sports specialty, it's imperative to foster its core competence which includes the integration of available resources, innovation of talents cultivation mode, stimulation of teachers' subjective initiative and creation of distinctive brand.
\end{abstract}

Keywords-leisure sports; core competence; specialty development strategy

\section{INTRODUCTION}

There have been 16 undergraduate universities that have set up leisure sports specialty since established by the Ministry of Education, however, the cultivation of talents in leisure sports major is still at a groping stage. According to the investigation, the cultivation of talents in leisure sports major currently is mostly based on the mode for the cultivation of social sports talents, such as the curriculum setting, staff arrangement, teaching site, etc., which not only is unhelpful for the students' employment but also affects the direction of specialty development. Therefore, proceeding from the development and talents training of leisure sports specialty and using the core competence theory, this paper has created the leisure sports talents training mode and specialty development direction able to reflect its characteristics and value, thereby providing reference for the construction of leisure sports discipline.

\section{ORgAniZATION OF THE TEXT}

\section{A. Connotation of core competence and major core} competence

\section{1) Connotation of core competence}

Competence is a comparative term, referring to different subjects' external force[1] displayed during the process of achieving their goals, which is the reflection of individual characteristics and reflects the value of individual performance to some extent. The competition between individuals or organizations is actually the confrontation of core competences[2]. The core competence was first proposed by
C.K.Prahalad and Gary Hamel, reflective of an enterprise's competitive advantage over his rival and their core competence difference[3], characterized by the nature of value, scarcity, irreplaceability and inimitability. As can be seen from the concept, the theory of core competence demonstrates its strength from inside to outside, which means acting according to circumstances, integrating internal resources, giving full play to the strong points and leading the era development so as to enable the individuals or organizations to bring out the best in themselves.

\section{2) Connotation of major core competence}

At the beginning of this century, the core competence theory was introduced into the education, but most studies on which are from the macroscopic aspect. Even though tactics have been provided for the strategic development of colleges and universities, the research on universities' majors and disciplines by using core competence theory is still at the stage os exploration. In line with the core competence theory, many scholars conduct the research on specialty constitution and structure by taking universities' majors as subject, for instance: some research suggests that as specialty being the principal part of competition, it is the competence that promotes the positive development of the specialty and among the competitive factors constituting the specialty, it is the key factor that constitute the core competence ${ }^{[4]}$ of the universities' specialty.

\section{B. Concept and characteristics of the core competence of leisure sports specialty}

1) Concept of the core competence of leisure sports specialty and its demonstration

In 2007, the Ministry of Education listed the leisure sports into the undergraduate admission catalog, and in the same year, Wuhan Institute of Physical Education and Guangzhou Sport University started to take in undergraduates majoring in leisure sports, which marks the beginning of the construction of leisure sports specialty. According to principles of the core competence theory and research on the competence of other specialties, the paper interprets the core competence of leisure sports specialty as: the core competence of leisure 
sports specialty refers to the comprehensive capacity which is formed based on the integration and full use of the universities' teacher resources, hardware facilities and regional environments under the guidance of leisure philosophy and market's demand for talents, able to actively exploit the advantages to the full in the internal and external competitions. The comprehensive capacity is composed of numerous sub factors which can be reflected in the process of specialty development: the core advantage of "we have and the better ones". The core competence of leisure sports specialty is derived from the comparison with peer universities. Different types of universities can show their superiorities in some respects, such as the accumulation of specialty construction, university popularity, application of teaching and training hardware, etc., however, the result of competition mainly depends on the cultivation of talents in leisure sports major, scientific research achievements and rate of contribution to the leisure sports development. The core competence of leisure sports specialty has been demonstrated in the following three aspects:

First of all, the core competence of leisure sports is derived from the comparison and it's the superior capacity displayed in the process of its competition with peer professions, which, based on the analysis of comparative subjects, is the competitive advantage unique to leisure sports specialty and is precipitated over the years, inimitable and sustainable, not an external or static expression.

Next, the core competence of leisure sports is also demonstrated in the capacity of seizing market opportunity. The so-called market opportunity refers to the existing demands that haven't been met or have't been fully met on the market [5]. While the survival and development of leisure sports specialty involves, under the guidance of market needs, setting up the philosophy of schooling as well as optimizing the configuration of human resources, software and hardware. It' $s$ required to not only ensure talent training adapted to market requirements but also ensure the dominant position in the course of competition. Seizing market opportunity is mainly reflected in the effective response to the market. Currently, the job market for leisure sports majors is vast and diversified, such as gymnasium coaches in various types of business fitness centers and sports venues: but these orientations have some shortcomings including low recruit standard, large mobility, etc., which requires the current leisure sports specialty to shift the idea and aim at the leisure sports projects with high recruit standard for talent cultivation. It' $s$ essential to be forward-looking during the cultivation of talents and strive to run ahead of other peer institutions with the same profession in talent training, thereby enhancing the core competence of leisure sports specialty.

Furthermore, it's demonstrated in the objects of subject development. The competition between specialties is reflected in the competition of hardware and software on one hand and in the cultivation of talent training on the other hand, which is different from the corporate core competence which aims to pursue the profit maximization. As a professional talent training organization, the specialty is always taking the market demand as guidance and the cultivation of talents approved by the market as purpose. Whether high-level talents can be cultivated and whether a promising talent training direction can be initiated are key to the competitive advantage related to the sustainable development of a specialty. Since with short period of leisure sports specialty construction and no experience for reference, the leisure sports specialty is still at the stage of exploration and has many problems regarding the talent training compared with other specialties in physical education discipline. Meanwhile, leisure sports belongs to the entertainment industry, which means it has lower threshold, thereby leading to the leisure sports majors competing with the talents in social sports specialty, sports education specialty and traditional ethnic sports specialty. Leisure sports majors have to bear higher pressure from employment. To gain an advantage in the fierce competition, the leisure sports specialty must foster the core competence.

2) The features of leisure sports specialty in core competence

According to the theory of core competence, it is characterized by value, scarcity, irreplaceability, and inimitability. Forming the core competence of leisure sports must have these four features.

a) Value: The features of Leisure Sports Specialty in core competence are mainly manifested in the following three aspects. The first is subjectivity, that is Leisure Sports Specialty's own development needs, for leisure sports develops unevenly in various universities, and all the regions. In the fierce competition fighting for survival and development, leisure sports must cultivate core idea conducive to the development of this major, talent training direction, and academic status. The second is objectivity, for the measure value of leisure sports is through the feedback of the objective world, and society's approval rankings of talents cultivation, academic status, professional rank etc. are the results after compared with the counterparts. Only the subject makes great efforts, brings the initiative into full play, and establishes the core values, the objective evaluation will be high. The third is sociality. Leisure Sports Specialty competition eventually through serving society, reflects its actual value. Only adapting to the social development, and orienting for the social demands of talents, leisure sports can develop rapidly.

b) Scarcity: Leisure Sports Specialty core competence is mainly the integration results of talents training, scientific research, social service and other indicators. With the increase of statutory holidays and the promulgation of Workers paid leave regulations, people's leisure right has been guaranteed by law. However, the current leisure service personnel and the related issues are remained to be researched, which provide a chance for leisure sports' existence and development. Up to now, there are only 16 colleges throughout the country establishing the leisure sports major, which shows the scarcity of this major. Besides, the colleges directions of the leisure sports major are set differently, for example, Huaihai Institute 
of Technology and Hainan Normal University nurture talents related with marine related direction; Nanjing Institute of Sports' main direction is about golf; Shenyang Institute of Sports mainly is mainly oriented for the snow to train leisure talents; Changzhou University takes the indoor fitness as the direction to train leisure talents, and these universities take the scarcity on purpose to start training leisure sports talents to demonstrate their core competence.

c) Irreplaceability: Leisure sports is set up in order to meet the needs of the public leisure, which the major related with the public leisure has entered the higher education for the first time, and at the same time, reveals leisure sports' uniqueness and irreplaceability. Besides, leisure sport has a long history, with its own theoretical system, personnel training specifications, and employment channels, which is different from Human Sport Science, Sports Humanistic Sociology and Physical Education Training. From the visual analysis of peer competition, 16 colleges setting up leisure sports all have their own advantages and features, and they are different from each other on personnel training, sports cultural accumulation and students' employment, and they cannot replace each other.

d) Inimitability: Leisure sports opened in the sports colleges, on the one hand, competes with other majors of sports discipline, especially in terms of students' employment and academic status. On the other hand, this kind of competition is mainly shown in the aspects of student resources, related resources, student employment etc. To stand in the competition, colleges must build the core competence, which is the show from the inside to the outside, for example, leisure sports in several colleges has opened underwater swimming relying on sea. This has found the suitable direction of personnel training, and whether it can form the core competence can be tested by time. Relying on college geography, regional characteristics, colleges gradually enhance their core competence, and this competence is difficult to imitate, because the formation of this competence is often attributed to geography, school history, teachers and so on.

\section{Strategies for the fostering of core competence of leisure sports specialty}

1) Integration of available resources and innovation of talents training mode

Most talents in leisure sports major are service-oriented personnel who have been put into different categories with uneven level of employment, which is unfavorable for the specialty's training direction: such as golf, powerboat and paraglider orientations, which are difficult to establish just depending on the universities' current resources, but these orientations are within the scope of leisure sports and the corresponding professional service personnel is insufficient, it's of great significance to offer these courses and it's pretty favorable for the formation of core competence. Therefore, universities shall cultivate the talents by combining with enterprises and relevant foreign institutes and give full play to their own advantages in scientific research and human resources, with the help of cooperators' field, experience and equipment, etc., thereby creating the core competence.

\section{2) Stimulation of teachers' subjective initiative}

In modern society, the quantity and quality of teachers occupy an important position in the competition between universities. The fostering of core competence of leisure sports can not do without high-level experts and professors. Great importance shall be attached to the construction of highquality teaching staff for the fostering of core competence of this specialty. Human is the most active factor of production, and people-oriented core value suggests to give full play to the people's subjective initiative and promote teachers' devotion in the process of major construction. As the leisure sports specialty is a newly-developing major, faculty deficiency is a realistic problem that every university has to face. Therefore, universities shall apply the method of "taking in experts from outside with training inside" in teacher cultivation. Meanwhile, balance shall be guaranteed during the cultivation process: since most posts require students graduating from leisure sports major possessed of certain operation skill and service level, it's important to introduce and cultivate the practice-oriented personnel with skills or management experience while during the introduction and cultivation of high-quality theory teaching and research staff.

\section{3) Creation of distinctive brand}

It has been less than a decade since the establishment of leisure sports specialty which is newly developing with little difference between various universities. Thus, universities shall create featured and distinctive brand according to their own characteristics and take leisure sports as the breakthrough point of program requirement, thereby improving their status among similar institutions. At present, the nationally wellknown fancy rope skipping course offered in Shanghai University of Sport has greatly enhanced the influence of its leisure sports specialty. Creating distinctive brand is an effective way to foster the core competence, which requires all universities to dig in the traditional leisure sports, seek in the modern leisure sports and explore in the developing leisure sports.

\section{REFERENCES}

[1] Li Jianning, Evaluation Research on Discipline Competitiveness of Universities [D], Shanghai, East China Normal University, 2004: 18- 26.

[2] Du Gang, Cui Ting, Study on Levels of the Core Competence of Enterprise - Dimension Structure as well as Its Evaluation and Determination Model [J], Science of Science and Management of S\&T, 2005(1): 138- 142 .

[3] C.K. Prahalad, G. Hamel, The Core Competence of the Corporation [J], Harvard Business Review, 1990(6): 79-91.

[4] Zhang Shisen, Ouyang Yun, Core Competency of MBA of Harvard [M], Hohhot, Yuanfang Press, 2003: 6- 7, 135.

[5] Zhang Maolin, Yu Dinghai, Core Competence and Cultivation Strategy of Traditional Ethnic Sports Discipline in Institutes of Physical Education [J], Journal of Shanghai University of Sport, 2010, 4(1): 5861.

[6] Liu Quan, Zou Xiaodong, Exploration of the Core Competence of University Discipline [J], Liaoning Education Research, 2004(2): 21. 
[7] Zhou Jin, Core Competence of Disciplines in Universities [J], Science \& Technology Review, 2001(10): 14. 